University of Nebraska - Lincoln

DigitalCommons@University of Nebraska - Lincoln

CSE Conference and Workshop Papers

Computer Science and Engineering, Department

2001

\title{
Optimization of Amplifier Placements in Switch-Based Optical Networks
}

Ling Zong

Microsoft Corp.

Byrav Ramamurthy

University of Nebraska-Lincoln, bramamurthy2@unl.edu

Follow this and additional works at: https://digitalcommons.unl.edu/cseconfwork

Part of the Computer Sciences Commons

Zong, Ling and Ramamurthy, Byrav, "Optimization of Amplifier Placements in Switch-Based Optical Networks" (2001). CSE Conference and Workshop Papers. 119.

https://digitalcommons.unl.edu/cseconfwork/119

This Article is brought to you for free and open access by the Computer Science and Engineering, Department of at DigitalCommons@University of Nebraska - Lincoln. It has been accepted for inclusion in CSE Conference and Workshop Papers by an authorized administrator of DigitalCommons@University of Nebraska - Lincoln. 


\title{
Optimization of Amplifier Placements in Switch-Based Optical Networks
}

\author{
Ling Zhong* and Byrav Ramamurthy+ \\ *Microsoft Corp., One Microsoft Way, Redmond, WA 98052-6399, USA \\ + Dept. of Computer Science \& Engineering, University of Nebraska-Lincoln, USA \\ Email: lingz@microsoft.com, byrav@cse.unl.edu
}

\begin{abstract}
Wavelength division multiplexing (WDM) offers a solution to the problem of exploiting the large bandwidth on optical links; it is the current favorite multiplexing technology for optical communication networks. Due to the high cost of an optical amplifier, it is desirable to strategically place the amplifiers throughout the network in a way that guarantees that all the signals are adequately amplified while minimizing the total number amplifiers being used. Previous studies all consider a star-based network. This paper demonstrates an original approach for solving the problem in switch-based WDM optical network assuming the traffic matrix is always the permutation of the nodes. First we formulate the problem by choosing typical permutations which can maximize traffic load on individual links; then a GA (Genetic Algorithm) is used to search for feasible amplifier placements. Finally, by setting up all the lightpaths without violating the power constaints we confirm the feasibility of the solution.
\end{abstract}

Keywords: WDM, Switch-based optical network, permutation routing, lightpath, Routing and Wavelength Assignment (RWA), Capture Link Traffic, Genetic Algorithm, Smallest Gain First Algorithm.

\section{INTRODUCTION}

Optical amplifiers are needed to compensate for the power losses in a WDM network. The optimization of amplifier placements problem can be stated as following: given a network topology, decide the minimum number of amplifiers and their exact locations on every link so that all lightpaths can be routed successfully without violating the power constraints.

An optical amplifier has constraints on the maximum gain and the maximum output power it can supply; optical amplifier placement problem is a mixedinteger nonlinear problem which is difficult to solve. Previous studies on amplifier placement problem [4] all belong to local network design domain in which passive stars are used. The solutions are inadequate for configurable wavelength-routed wide area networks (WANs) because of the broadcast nature and the lack of wavelength reuse in a local star-based network. In this paper, we study the problem of optimal placements of amplifiers in a switch-based WDM optical network assuming arbitrary permutation traffic [1]. (Each node is the source and destination of one lightpath and the destinations of the lightpaths are always the permutation of the nodes.)

Our objective is to place the amplifiers on the fiber links in such a way that a minimal number of amplifiers are needed for successfully establishing all the lightpaths of an arbitrary permutation.

It is desirable to balance the traffic throughout the network in order to maximize optical amplifier utilization. Adaptive alternate shortest path (AASPR) [5] is proposed here as an efficient routing and wavelength assignment (RWA) algorithm to minimize the maximum number of wavelengths for each individual link.

In a switch-based WDM network, any possible traffic matrix may appear and it may change dynamically; as a result, the number of wavelengths used on each individual link may change accordingly; so the real difficulty here is how to find an optimal solution for all possible traffic matrices. In our studies, two heuristic approaches are used to solve this difficult problem. Three algorithms are used in the approaches, which are:

- Capture Link Traffic (CLT)

- Generic Algorithm (GA)

- Smallest Gain First (SGF) [2]

In this paper, we will first introduce the network model and system parameters; then give the summary of the solver strategy; after that, three algorithms are presented in sequence; finally a numerical example is given demonstrating how our approaches can solve the optimization of amplifier placements in a switch-based WDM optical network under arbitrary permutation traffic matrices; the results of the two heuristics are compared.

\section{SYSTEM DESCRIPTION}

\subsection{Network Model}

The network model used in our research is a typical wavelength-routed network. This network consists of a number of intermediate wavelength routing nodes (WRN) between source and destination access stations. Each WRN consists of a crossconnect switch (XCS), an input erbium-doped fiber amplifier (EDFA), an output EDFA, an optical power tap on both sides of the 
$\mathrm{XCS}$ at at each port, and a local access station. (see Figure 1). All the components inside WRN will introduce loss/gain to the signals passing by, as listed in Table 1.

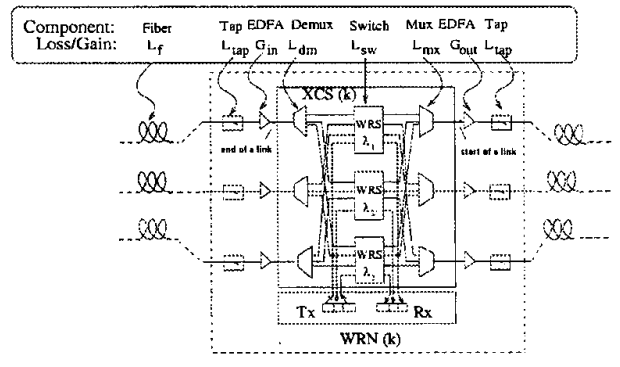

Figure 1: A wavelength routing node.

\subsection{Amplifier Gain Model}

Wide-bandwidth gain-flattened Erbium-doped fiber amplifiers (EDFAs) are chosen for both inline amplifiers and input/output amplifiers in our network model. We assume the amplifiers will have flattened gain [4], i.e., all wavelengths entering an amplifier will get same gain regardless of their power levels. Figure 2 gives the amplifier gain model used in this paper.

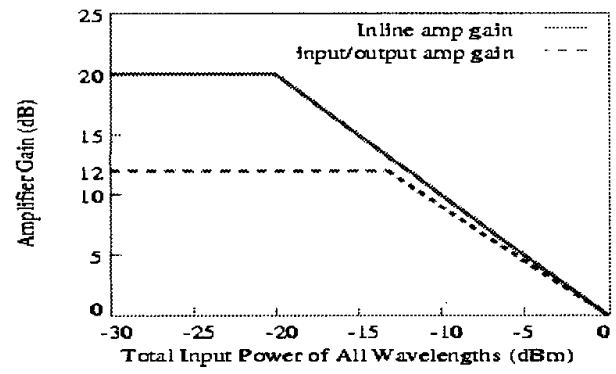

Figure 2: Amplifier gain model.

The gain function of the amplifier is given by: $G\left(G_{\max }, P_{i n}, P_{\max }\right)=\min \left(G_{\max }, T o D B\left(P_{\max }-P_{i n}\right)\right)$

Here, $G_{\max }$ is the maximum small-signal gain of an amplifier; $P_{i n}$ is the total input power on all wavelength in $\mathrm{mW} ; P_{\max }$ is the maximum output power of an amplifier in $\mathrm{mW}$.

\subsection{Power Constraints}

In our network model $G(V, E)$, the traffic matrix is always a permutation of the nodes [1]; there are at most $N(N=|V|)$ lightpaths in a traffic matrix. Each node (WRN) is the source of at most one lightpath and the destination of at most one lightpath. There are $N$ ! possible permutations, corresponding to $N$ ! possible traffic matrices. The problem is formulated assuming routing and wavelength for each lightpath is given because the gain of an amplifier is dependent on the precise mix of the power levels on all wavelengths.

The power constraints for the network can be stated in this way: both the total power level at the start and end of each device in the network should be within valid power level, which is no smaller than $p_{\text {sen }}$ and no larger than $P_{\max }$; the power level on each wavelength should also within the range between $p_{s e n}$ and $P_{\max }$.

The possible loss factors include fiber loss, and the loss by the components in the WRN; the possible gain factors include inline amplifier gain, input/output amplifier gain. Those components inside a WRN can be looked as components of the fiber links, so that we can change the start/end points of links. Instead of taking the points between two WRNs to be the start and end of a link, the point between multiplexer and output amplifier is taken as the start of a link, the point between the input amplifier and demultiplexer is taken as the end of a link (see Figure 1).

The total power $P_{i}^{i}($ in $\mathrm{mW})$ at the start of a component $i$ on a link $l$ is checked to make sure it is in the range between $p_{\text {sen }}$ and $P_{\text {max }}$. We also need to make sure that the power level $p_{l}^{i, w^{\prime}}$ (in $\mathrm{dBm}$ ) on individual wavelength $w$ ( $w$ is a wavelength passing through link $l$ ) is valid.

To generate the power constraints, each link is divided into $m+2$ components; in which $m$ is the number of amplifiers reside on that link. The following inequalities must be satisfied to avoid violating the power constraints.

$$
\begin{gathered}
p_{\text {sen }} \leq p_{l}^{i, w} \leq \operatorname{ToDB} \quad\left(P_{\max }\right) \quad i \in[1,4] \quad w \in[1,2] \\
P_{i}^{\prime}=\operatorname{ToMW} \quad\left(p_{i}^{i, 1}\right)+\operatorname{ToMW} \quad\left(p_{i}^{i, 2}\right) \quad i \in[1,4] \\
\operatorname{ToMW}\left(p_{\text {sm }}\right) \leq P_{i}^{i} \leq P_{\max } \quad i \in[1,4] \\
\text { where } \mathrm{i}, w \text { are integers. }
\end{gathered}
$$

\section{SOLUTION APPROACH}

Figure 3 gives the summary solver strategy; these are two heuristic approaches - each includes three modules, as explained below:

I. CLT-- A heuristic method that aims at capturing the link traffic by choosing a small subset of the permutations that is known to maximize the loads on individual links based on the network topology and the result of the RWA algorithm.

II. Running Genetic Algorithm (GA) to search for feasible amplifier placements, which can satisfy the power constraints for the chosen subset of permutations. 
In heuristic approach I, SGF is used to test the fitness of the amplifier placements; it tries to allocate the lowest

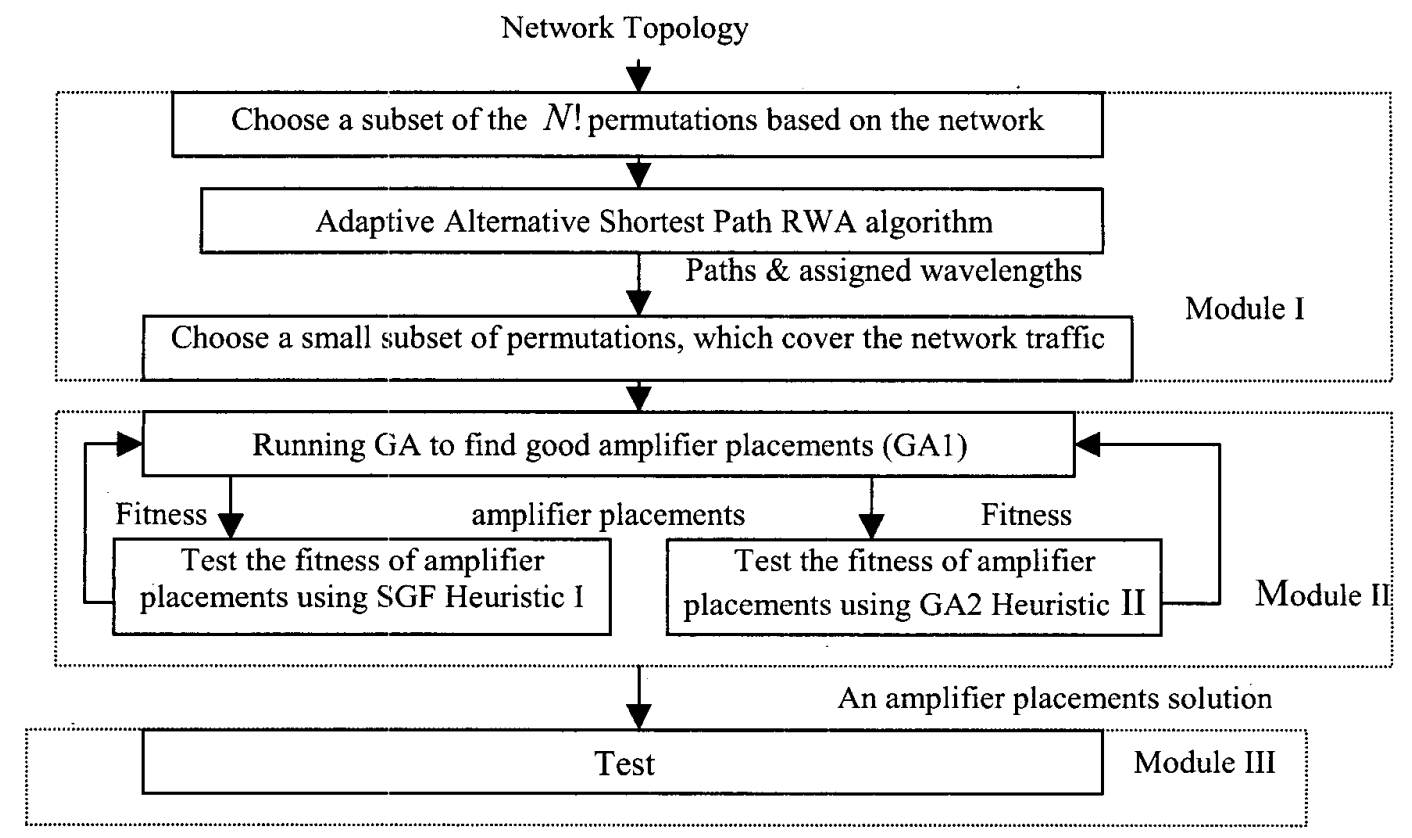

Figure 3: Solver strategies for optimization of amplifier placements problem in an All Optical Network (AON).

possible transmission power for all the lightpaths. In heuristic approach II, GA is used again to test the fitness of an amplifier placement by searching for a possible transmission power for each individual lightpath. We will call the outer layer of GA as GAl and call the inner layer of GA as GA2 in this paper.

III. Place the amplifiers on the example network according to the solution found in step II; use arbitrary permutations to test the correctness of the solution.

\subsection{The Capture Link Traffic (CLT) Method}

The CLT heuristic aims at choosing a small subset of the $N$ ! permutations to find the maximum number of wavelengths for each individual link. It includes the following steps:

i. Find the shortest paths for all possible connection requests (lightpaths).

ii. Sort all the lightpaths according to the length of their shortest paths.

iii. Choose the first few longest lightpaths as the fixed lightpaths, which will definitely be chosen; compute the permutation of the other nodes; the chosen permutation sets include the fixed lightpaths and the lightpaths from the permutations of the other nodes.

iv. Run adaptive alternative routing and wavelength assignment algorithm (AASPR) [5] to find the max_wav on each individual link for all the chosen permutations. Choose a small group of permutations whose combination can cover the max_wav on each individual link as the input of our second module: GAl.

\subsection{Genetic Algorithms (GA)}

Genetic algorithm are searching and optimizing algorithms that try to resemble the mechanics of natural selection and natural genetics [3]. The algorithm starts with a population of individuals sorted according to their fitness; the two individuals with the highest fitness are selected as the parents; certain functions are used to combine parents with a structured yet randomized information exchange to form a child; then the child is inserted in the population according, to their fitness. The population reaches the second generation after certain percentage of individuals are updated; the same mechanism is used to create the third generation, etc. This adaptation repeats until a value with satisfying fitness is found or no noticeable improvement can be made after some generations. Three operators (Reproduction, Crossover, Mutation ) are used in a simple GA [3].

\subsubsection{GA Implementation in Amplifier Placements Problem: GA1}


In GA literature, a solution is called a chromosome. In our problem domain, all the fiber links in the network are numbered; they are considered jointly as a long fiber in the order of their numbers. The chromosomes are a set of $m$ real numbers, each represents the distance from an amplifier to the next amplifier throughout the network; minimum power needed for a lightpath to reach the first inline amplifier); if this value is so small that the power level on this lightpath drops below $\mathrm{p}_{\mathrm{sen}}$, later GA2 will do a neighborhood search by adding small increments to $\mathrm{p}_{\text {min }}$; in this way, a group of individuals

\begin{tabular}{|c|c|c|}
\hline Parameter & Description & Value \\
\hline$P_{\max }$ & $\begin{array}{c}\text { Maximum power available from an amplifier and an transmitter; Maximum } \\
\text { aggregate power on a link }\end{array}$ & $1 \mathrm{~mW}(0 \mathrm{dBm})$ \\
\hline$p_{\text {sen }}$ & Minimum signal power detectable by amplifier and receiver. & $-30 \mathrm{dBm}$ \\
\hline$G_{\text {max } i n l i n e}$ & Maximum (small signal) inline amplifier gain & $20 \mathrm{~dB}$ \\
\hline$G_{\max _{i} \text { in }}$ & Maximum (small-signal) gain of input amplifier & $12 \mathrm{~dB}$ \\
\hline$G_{\max _{\text {out }}}$ & Maximum (small-signal) gain of output amplifier & $12 \mathrm{~dB}$ \\
\hline$a$ & Fiber loss & $0.2 \mathrm{~dB} / \mathrm{km}$ \\
\hline$L_{t a n}$ & Tap Loss & $1 \mathrm{~dB}$ \\
\hline$L_{m x}$ & Multiplexer loss & $4 \mathrm{~dB}$ \\
\hline$L_{d m}$ & Demultiplexer loss & $4 \mathrm{~dB}$ \\
\hline$L_{s}$ & Switch element insertion loss & $1 \mathrm{~dB}$ \\
\hline$L_{w}$ & Wavelength/fiber coupling loss & $1 \mathrm{~dB}$ \\
\hline
\end{tabular}

Table 1: System parameters used in this model.

they are also the solution for the amplifier placement problem. A chromosome is encoded and represented by a record called individual. The set of individuals are called population and are put in the mating pool. The quality of a chromosome is called its fitness. The fitness of the individual for our problem domain here is the total number of amplifiers in the network. The fewer number of amplifiers used in an amplifier placement, the higher fitness this placement has.

\subsubsection{GA Implementation in Amplifier Placements Problem: GA2}

GA2 is used in approach II to test the feasibility of an individual in GA1, which corresponds to an amplifier placement. The individuals in GA2 are the transmission powers of the $N$ lightpaths inside a permutation. GA2 searches for these values of transmission powers repeatedly; if all the lightpaths can be established without violating the power constraints, we say there is a match between the lightpath's transmission powers and amplifiers' locations on the links; a placement is feasible if such a match is found for an amplifier placement by GA2.

GA2 is an efficient way to search for the transmission powers for lightpaths; it starts with $\mathrm{p}_{\min }$ (the are generated, which are all candidates for the transmission powers; then GA2 tests the feasibility of these individuals by trying to establish all lightpaths.

\subsection{Smallest Gain First (SGF) Algorithm}

Assume that the number of amplifiers on each link and their exact locations are known in advance; given a set of lightpaths, if a feasible transmission power can be found for each lightpath, such that the power constraints of the network (see Section 2.3) can be satisfied, this amplifier placement is feasible. Moreover, a placement is more desirable if lower feasible transmission power for lightpaths can be found based on this placement. SGF aims at finding a better amplifier placement by assigning the minimum transmission power to every lightpath, then it will add all the lightpaths of the chosen permutation link by link according to their length (longest one first). In this way, it minimizes the possibility of amplifier saturation [4]. The problem here is this small transmission power level may in turn require more amplifiers during the signal transmission along the lightpaths. Our objective is to strike a balance between the two extremes for transmission power levels. 


\section{EXPERIMENTS}

The Pacific Bell network (see Figure 4) is chosen as the example to illustrate our approaches for solving the amplifier placement problem.

Both heuristics give a set of amplifier placements with the same characteristic of putting an amplifier on each individual link except link 9. Table 2 lists one placement computed by SGF and another one given by GA2. 5 permutations are randomly chosen to test the correctness of our heuristics; the result is all of the lightpaths can be successfully established without violating the power constraints and GA2 performs better than SGF by finding lower transmission powers for all the lightpaths.

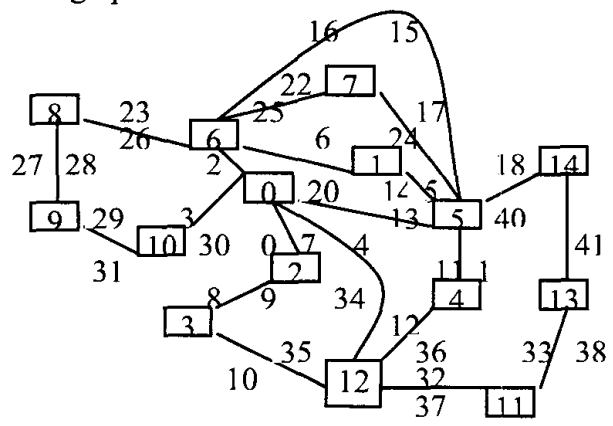

Figure 4: Pacific Bell Network; nodes are numbered from 0 to 14; links are numbered from 0 to 42 , each line represents a pair of unidirectional fibers.

\begin{tabular}{|c|c|c|c|}
\hline $\begin{array}{c}\text { Link } \\
\text { ID }\end{array}$ & $\begin{array}{l}\text { Amplifier } \\
\text { numbers }\end{array}$ & $\begin{array}{c}\text { Amplifier's } \\
\text { distance from } \\
\text { link source(SGF) }\end{array}$ & $\begin{array}{c}\text { Amplifier's } \\
\text { distance from } \\
\text { link source }(\mathrm{GA} 2)\end{array}$ \\
\hline 0 & 1 & $38.00 \mathrm{~m}$ & $62.80 \mathrm{~m}$ \\
\hline 1 & 1 & $38.00 \mathrm{~m}$ & $62.80 \mathrm{~m}$ \\
\hline 2 & 1 & $38.00 \mathrm{~m}$ & $41.87 \mathrm{~m}$ \\
\hline 3 & 1 & $36.72 \mathrm{~m}$ & $41.87 \mathrm{~m}$ \\
\hline 4 & 1 & $36.02 \mathrm{~m}$ & $45.46 \mathrm{~m}$ \\
\hline 5 & 1 & $49.77 \mathrm{~m}$ & $45.46 \mathrm{~m}$ \\
\hline 6 & 1 & $49.77 \mathrm{~m}$ & $45.46 \mathrm{~m}$ \\
\hline 7 & 1 & $49.77 \mathrm{~m}$ & $45.46 \mathrm{~m}$ \\
\hline 8 & 1 & $42.28 \mathrm{~m}$ & $45.46 \mathrm{~m}$ \\
\hline 9 & 0 & - & \\
\hline 10 & 1 & $61.44 \mathrm{~m}$ & $60.89 \mathrm{~m}$ \\
\hline 11 & 1 & $61.44 \mathrm{~m}$ & $74.93 \mathrm{~m}$ \\
\hline 12 & 1 & $63.72 \mathrm{~m}$ & $74.93 \mathrm{~m}$ \\
\hline 13 & 1 & $63.72 \mathrm{~m}$ & $74.93 \mathrm{~m}$ \\
\hline 14 & 1 & $63.26 \mathrm{~m}$ & $74.93 \mathrm{~m}$ \\
\hline 15 & 1 & $52.69 \mathrm{~m}$ & $74.93 \mathrm{~m}$ \\
\hline 16 & 1 & $52.69 \mathrm{~m}$ & $74.93 \mathrm{~m}$ \\
\hline 17 & 1 & $52.69 \mathrm{~m}$ & $50.18 \mathrm{~m}$ \\
\hline 18 & 1 & $52.69 \mathrm{~m}$ & $50.18 \mathrm{~m}$ \\
\hline 19 & 1 & $52.11 \mathrm{~m}$ & $50.18 \mathrm{~m}$ \\
\hline 20 & 1 & $49.84 \mathrm{~m}$ & $50.18 \mathrm{~m}$ \\
\hline 21 & 1 & $49.84 \mathrm{~m}$ & $50.18 \mathrm{~m}$ \\
\hline
\end{tabular}

\begin{tabular}{|l|l|l|l|}
\hline 22 & 1 & $49.84 \mathrm{~m}$ & $50.18 \mathrm{~m}$ \\
\hline 23 & 1 & $49.84 \mathrm{~m}$ & $69.56 \mathrm{~m}$ \\
\hline 24 & 1 & $49.84 \mathrm{~m}$ & $69.56 \mathrm{~m}$ \\
\hline 25 & 1 & $49.84 \mathrm{~m}$ & $69.56 \mathrm{~m}$ \\
\hline 26 & 1 & $34.68 \mathrm{~m}$ & $69.56 \mathrm{~m}$ \\
\hline 27 & 1 & $40.19 \mathrm{~m}$ & $58.39 \mathrm{~m}$ \\
\hline 28 & 1 & $38.54 \mathrm{~m}$ & $58.39 \mathrm{~m}$ \\
\hline 29 & 1 & $38.54 \mathrm{~m}$ & $58.39 \mathrm{~m}$ \\
\hline 30 & 1 & $52.24 \mathrm{~m}$ & $58.39 \mathrm{~m}$ \\
\hline 31 & 1 & $73.99 \mathrm{~m}$ & $58.39 \mathrm{~m}$ \\
\hline 32 & 1 & $73.99 \mathrm{~m}$ & $57.29 \mathrm{~m}$ \\
\hline 33 & 1 & $73.99 \mathrm{~m}$ & $57.29 \mathrm{~m}$ \\
\hline 34 & 1 & $62.44 \mathrm{~m}$ & $57.29 \mathrm{~m}$ \\
\hline 35 & 1 & $62.44 \mathrm{~m}$ & $57.29 \mathrm{~m}$ \\
\hline 36 & 1 & $62.44 \mathrm{~m}$ & $57.29 \mathrm{~m}$ \\
\hline 37 & 1 & $62.44 \mathrm{~m}$ & $57.29 \mathrm{~m}$ \\
\hline 38 & 1 & $67.54 \mathrm{~m}$ & $57.29 \mathrm{~m}$ \\
\hline 39 & 1 & $67.54 \mathrm{~m}$ & $63.28 \mathrm{~m}$ \\
\hline 40 & 1 & $58.58 \mathrm{~m}$ & $63.28 \mathrm{~m}$ \\
\hline 41 & 1 & $58.58 \mathrm{~m}$ & $63.28 \mathrm{~m}$ \\
\hline
\end{tabular}

Table 2: Two example amplifier placements computed by SGF and GA2

\section{CONCLUSION}

This paper proposes an original approach to optimize amplifier placements in a switch-based WDM optical network which is a totally new domain. Numerical results show that this is a promising method for minimizing amplifiers in a switch-based network for an arbitrary permutation traffic matrix.

\section{REFERENCES}

[1] W. Liang, X. Shen, "Permutation routing in alloptical product networks." Proc. of 3rd Workshop on Optics and Computer Science, San Juan, Puerto Rico, Lecture Notes in Computer Science, vol. 1586, Springer, pp. 831--844, April 1999.

[2] M. Ali, B. Ramamurthy, and J. S. Deogun, "Routing and wavelength assignment with power considerations in optical networks," in Proceedings, IEEE Globecom '99 Symposium on High-Speed Networks, (Rio de Janeiro, Brazil), December 1999.

[3] David E. Goldberg, "Genetic Algorithm in Search, Optimization, and Machine Learning", Reading, MA: Addison-Wesley, 1989.

[4] B. Ramamurthy, J. Iness, and B. Mukherjee, "Optimizing amplifier placements in a multiwavelength optical LAN/MAN: the equally powered-wavelengths case", IEEE/OSA Journal of Lightwave Technology, vol. 16, no. 9, pp. 1560--1569, September 1998.

[5] L. Zhong, "Optimization of Amplifier Placements in Switch-Based Optical Networks", Master Thesis, Dept. of Computer Science and Engineering, University of Nebraska, Lincoln, NE, 2000. 